\title{
Implications for Effective Ways of Conducting and Assessing Presentations in EFL Classes
}

\author{
Etsuko Shimo \\ Kinki University, Japan
}

\begin{abstract}
The purpose of this paper is to explore more effective ways of conducting and assessing presentations in English-as-a-foreign-language (EFL) classes. To this aim, the author discusses student reactions to presentation assignments as well as the results of comparisons between the teacher and student evaluations of the presentations in English classes at a Japanese university. The students practiced presentations repeatedly with different partners (i.e., simultaneous presentations) before making presentations in front of the whole class at the final stage. This paper suggests that providing step-by-step procedures in presentation assignments is as important as having students experience various presentation styles. Additionally, allowing students ample reflection time and dialogues with the teacher and among themselves may help students understand the objectives of the small steps in the assignments and the intended purpose of the assessment criteria.
\end{abstract}

Many current university students in Japan have had very few opportunities to make presentations in English prior to entering university. Many of them may have not even had very many chances to speak English in class at all (Apple, 2011). Since the so-called "period for integrated studies" started to be implemented in the school curriculum in 2000 (Ministry of Education, Culture, Sports, Science, and Technology [MEXT], 1999), students have been encouraged to do problem-solving activities, including research and presentation tasks, in Japanese. Information technology education is now part of the school curriculum (MEXT, 1999), and more and more students have had experience in creating PowerPoint slideshows before they enter university. However, it still seems to be the case in many secondary school English classes that students remain passive and listen to the teacher's explanation with few opportunities to speak in English with others (Nishino, 2009).

For these Japanese university students who have a limited experience of using English in meaningful and authentic situations such as presentations, it is important to have a step-by-step method of teaching presentations in English classes. Thus, in the author's classes, students made presentations repeatedly in different small groups (i.e., simultaneous presentations) before they presented in front of the whole class.

Language Education in Asia, 2011, 2(2), 227-236. http://dx.doi.org/10.5746/LEiA/11/V2/I2/A05/Shimo 
This paper investigates students' perceptions of the presentation assignment, as well as the teacher and student evaluations of the presentations. This discussion is expected to lead to suggestions for more effective ways of conducting and assessing presentations.

\section{Literature Review}

\section{Simultaneous Presentations}

The "simultaneous presentation" technique is similar to "speed dating" (Brown \& Diem, 2009; Martinez, 2008). Martinez (2008) explained that in speed dating, ten or more men and women participate and have a chance to talk to each other one-on-one for five minutes each.

Likewise, in simultaneous presentations, students make presentations repeatedly with different partners.

The simultaneous presentation is actually a frequently-used technique in Cooperative Learning (CL) classrooms (Jacobs, Power, \& Loh, 2002). Two of the CL principles are "simultaneous interaction" and "equal participation," which means that all students ideally participate in the task at the same time and to the same degree of engagement (Jacobs et al., 2002). When students make presentations simultaneously in pairs, one makes a presentation, one listens to the presentation, and then they switch roles; this technique can create an optimum situation for simultaneous interaction and equal participation. The listening student is the only person in the audience and is inclined to listen attentively in order to give feedback to the presenter at the end. The presenter is likely to be more serious in front of an attentive audience. In short, the simultaneous presentation can work as an effective $C L$ technique.

Furthermore, the simultaneous presentation is useful in increasing speaking practices and reducing performance anxiety (Brown \& Diem, 2009; Martinez, 2008). In the author's classes, students' limited experience of speaking practice and performance anxiety were the teacher's major concerns. Limited experience was suspected to be part of the cause of second language (L2) anxiety for the students, and it was theorized that repeated practice could help build confidence. When learners repeatedly experience situations that make them anxious speaking in the L2, they are conditioned to feel anxious whenever they speak in the L2 (Maclntyre \& Gardner, 1989). In order to avoid such conditioning, it is helpful to provide a less threatening learning environment (Brown \& Diem, 2009; Horwitz \& Young, 1991; Martinez, 2008; Young, 1999).

\section{Assessment Method}

A major concern for assessment of simultaneous presentations is that the teacher often cannot watch presentations in person. For example, in the author's classes, there were 15 pairs in one class making presentations simultaneously. If the teacher had wanted to observe every student's presentation, students would have had to repeat their presentations 15 times. Such repetition may not be impossible, but does not seem to be realistic, effective, or motivational. If students made improvements over the 15 performances, then they could benefit from this repetitive experience. However, in this case, students whose presentations were evaluated later would have an advantage, which would not be fair to the other students.

To solve this problem, peer assessment was used by Brown and Diem (2009). Peer assessment is often said to have a problem in its reliability. For example, Cheng and Warren (2005) found that students' peer assessments did not always coincide with the teacher assessment and suggested that practice might have helped students to improve their peer assessment techniques. 
Regardless of assessment methods, it is important to inform students of what elements constitute a satisfactory achievement of the assignment in order for them to achieve a successful result in the assignment and gain the most knowledge and skills from the learning experience. In a study with business undergraduate students, Rust, Price, and O'Donovan (2003) reported that when students attended an assessment workshop in which they marked sample assignments, discussed the sample assignments in groups, and listened to a tutor's explanation about assessment criteria, they achieved significantly better results in their course.

Moreover, research has been conducted on student viewpoints about assessment criteria (e.g., Orsmond, Merry, \& Reiling, 2000; Otoshi \& Heffernen, 2008). Otoshi and Heffernen (2008) concurred with Orsmond et al. (2000) on the importance of involving students in creating assessment criteria for more effective learning, but at the same time, cautioned that teachers have to be careful about adopting student-derived assessment criteria.

In a study with university biology majors, Orsmond et al. (2000) claimed that learning outcomes may differ when assessment criteria are prepared by a teacher and when created by students; the purposes of the activity might be different in the two situations. The researchers also reported that students tried harder to understand what each of the teacher-prepared criterion meant compared to the student-derived ones. In addition, discussion between the course assessor and students, as well as among students, is important (see also Rust et al., 2003). It is important for teachers to provide criteria that help students develop the skills that they should be developing, and to discuss the criteria with the students or let the students discuss the criteria among themselves to help them understand what each criterion means.

In the author's classes, teacher evaluation was mainly used for course grades, while students' self- and peer assessment was mainly for the purpose of raising their awareness about the assessment criteria, i.e., the important elements for successful presentations. Peer assessment activities were also expected to help students in the audience pay close attention to the presentations. The teacher was concerned that students had not had enough training in assessment; therefore, since students' self- and peer assessment might lack in reliability, the portion of self-assessments was minimized and peer assessments were not used for course grading. The assessment criteria were prepared by the teacher and presented to the students with written and oral explanations. (See the Presentation Assessment Method section for more details of how presentation assessment was implemented in the author's classes.)

\section{The Study}

\section{Data Collection}

The research data was collected from two groups: Class A and Class B taking a course titled "English Seminar." Students took English Seminar 1 in the first semester (spring) and English Seminar 2 in the second semester (fall) with the same teacher and were given similar presentation assignments in both semesters. A questionnaire in the students' mother language, Japanese, was administered at the end of each semester to collect their reactions to the presentation assignments. Responses were collected from 49 students in the spring semester and 47 students in the fall. The data from the spring semester was discussed in Shimo (2010); this paper will focus on the data from the fall semester survey (see appendix). In addition, the students' self-evaluations and the teacher's evaluations in the fall semester will be compared. 


\section{Students and Their Learning Context}

The English proficiency levels of students in English Seminar Classes A and B ranged from higher intermediate to advanced (Figure 1). There were 15 psychology and 14 environmental studies majors, for a total of 29 students in Class A, and 30 socio-mass media majors in Class B. All students in both classes were native speakers of Japanese.

The goal of the English Seminar course was to promote basic comprehensive English abilities. The class met twice a week for ninety minutes each session, once in a traditional classroom with audio equipment at the teacher's desk, and once in a computer room. Students did various activities, including writing essays and reading passages using a textbook that had 20 chapters about social issues. Presentation assignments accounted for $15 \%$ of the course grade in both semesters, with the remaining $85 \%$ comprising quizzes, exams, essays, and many other in-class and out-of-class assignments.

\section{Presentation Requirements and Performance}

For the presentation assignments, students were required to: (a) make either a newsletter (one B4 size page or more) or a PowerPoint presentation (five slides or more), (b) choose a chapter from the textbook for their presentation, (c) include a summary of the chapter and additional information that they searched for and collected, and (d) make a three- to five-minute presentation. Students made their presentations in a computer classroom.

Students simultaneously performed presentations in pairs several times in the same class meeting. First, one student in a pair became a presenter (Student A) and the other a listener in the audience (Student B), and then they exchanged roles. Student $A$ then moved to a different seat and repeated this process with a new partner (Figure 2 ). In these pair presentations, students recorded their presentations using recording software. At the end of their final presentation day, they chose their best performance and turned in the electronic file to the teacher along with a hard copy of their presentation materials.

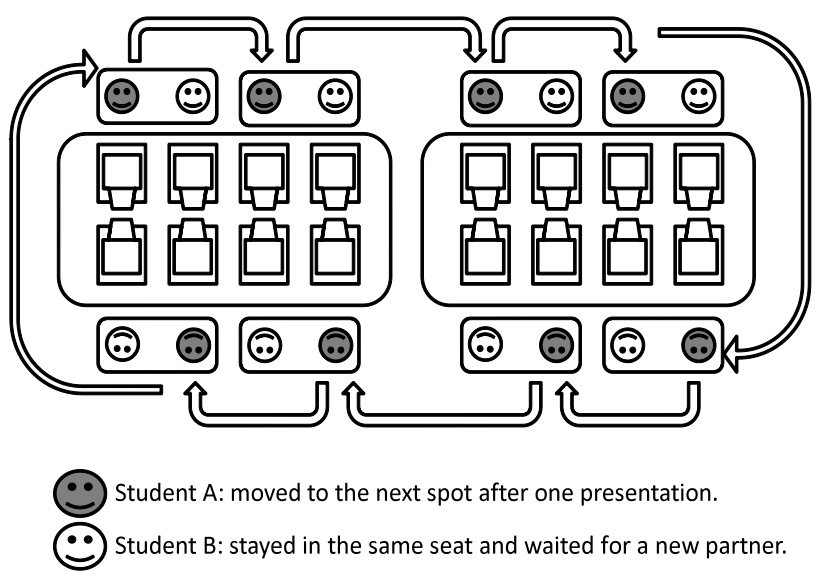

Figure 2. Pair presentation method (Shimo, 2010)

In the spring semester, students had seven pair presentations, including three in rehearsal and four in the final stage; they presented to seven partners. In the fall semester, all students were required to present in front of the whole class after four pair presentations, two in rehearsal and two "final." The teacher used the term final for the last two pair presentations before the 
whole-class presentations to encourage the students to make improvements from rehearsal to the final stage (Table 1).

\section{Table 1}

Presentation Steps Taken in the Spring and Fall Semesters

\begin{tabular}{llll}
\hline Step & Activity & Spring Semester & Fall Semester \\
\hline 1 & $\begin{array}{l}\text { Presentation guidelines } \\
\text { provided for students }\end{array}$ & Mid June & End of September \\
2 & $\begin{array}{l}\text { Pair presentations in } \\
\text { rehearsal }\end{array}$ & $\begin{array}{l}1^{\text {st }} \text { week of July: } \\
\text { three times in different pairs }\end{array}$ & $\begin{array}{l}2^{\text {nd }} \text { to last week of October: } \\
\text { two times in different pairs }\end{array}$ \\
3 & Final pair presentations & $\begin{array}{l}2^{\text {nd }} \text { week of July: } \\
\text { four times in different pairs }\end{array}$ & $\begin{array}{l}\text { Last week of October: } \\
\text { two times in different pairs }\end{array}$ \\
& Presentations in front of & ----- & $\begin{array}{l}\text { November to December: } \\
\text { class }\end{array}$ \\
& & & $\begin{array}{l}\text { a few students per class over } \\
\text { several weeks }\end{array}$ \\
\hline
\end{tabular}

\section{Presentation Assessment Method}

In the fall semester, four criteria were set and announced to the students along with the presentation guidelines: content (5 points), comprehensibility (5 points), time length (5 points), and improvement (5 points). The first three were adopted from the spring-semester presentation assignments. For each criterion, a brief explanation was given to students:

- Content: Is the presentation interesting and informative?

- Comprehensibility: Is the presentation easy to follow and understand?

- Time length: Is the presentation time sufficient? (Less than two minutes $=1$ point, two minutes $=3$ points, three to five minutes $=5$ points)

- Improvement: How did you improve your presentation after rehearsal?

Students were asked to evaluate their own and their classmates' presentations each time so that both presenters and audience would focus more on these assessment criteria.

In the fall semester, the teacher evaluated the students' performance in the final pair presentations using the first three criteria in the same way as in the spring: by listening to the students' recorded presentations, which were submitted as an electronic audio file, while referring to their hard copies of presentation materials ( 15 points in total). The students' selfevaluations about improvement from rehearsal to final pair presentations ( 5 points) were also added when calculating course grades. The total of 20 points in the steps of pair presentations accounted for $5 \%$ of the course grade, and so students' self-evaluation points were eventually reduced to $1.25 \%$ of the entire course grade. The teacher also directly evaluated students' very final presentations in front of the whole class, using the first three criteria (15 points), and this evaluation accounted for $10 \%$ of the course grade. Thus, the presentation assignments as a whole accounted for $15 \%$ of the entire course grade. 


\section{Data and Discussion}

\section{Student Reactions to Presentation Methods}

Students generally agreed that rehearsing pair presentations twice was useful for their learning, but fewer students agreed about the two final pair presentations (Figures 3 and 4). Many of the student comments revealed that they appreciated these steps, similar to Shimo (2010), because they were able to practice more, receive feedback, and check where to improve in a relaxed atmosphere in a small group. On the other hand, a few students stated that presenting to one person is so different from presenting to the whole class that it did not help them get ready for the final stage.

Next, more students - 14 students compared to nine and six in the previous stages respectively - agreed or strongly agreed that the whole-class presentation was useful (Figures 3, 4, and 5). There was also slightly more variety in responses (Figure 5). Students who responded positively often commented that it was a good learning experience, or that they were able to learn from other classmates' presentations. For negative responses, two said that they ended up simply repeating what they did previously, and two pointed out that there was overlapping in the choice of topics and therefore there were repeat performances of similar presentations.

Finally, ten students wrote suggestions about how presentation assignments can be designed. Three students commented that part of the pair presentations were not necessary. Perhaps some students needed more guided reflection time so they could make improvements between the repeat performances in order to better comprehend how they could benefit from this experience. Four commented on the whole-class presentation: one said it was very good, two said it was not necessary for everyone to do it, and one said it would have been better to do it in a traditional classroom. Various student preferences and motivation levels

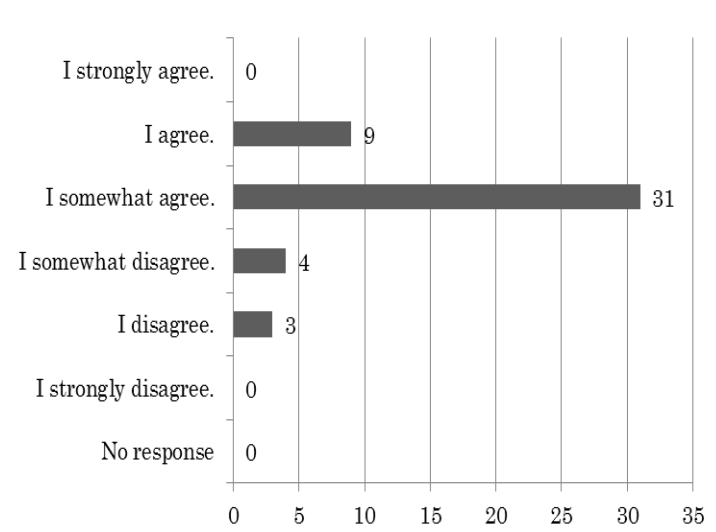

Figure 3. Rehearsal in two pairs: useful for learning? $n=47$.

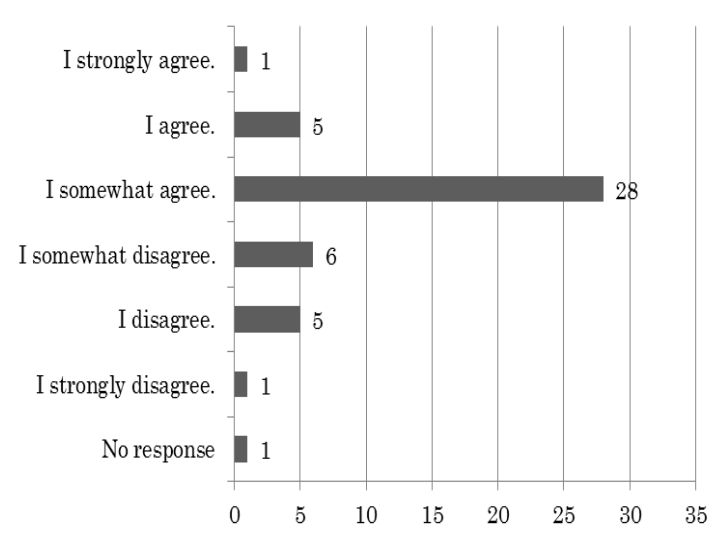

Figure 4. "Final" in two pairs: useful for learning? $n=47$.

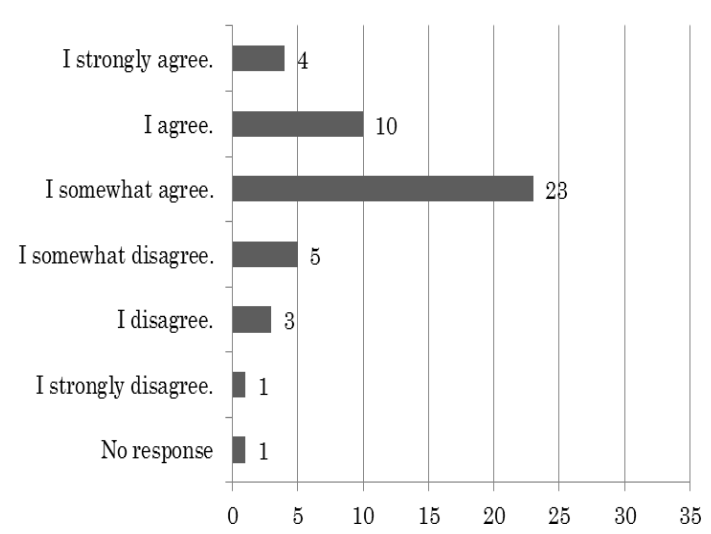

Figure 5. In front of the whole class: useful for learning? $n=47$. for learning seem to have been reflected in these different responses. The other three comments were: "[It is good to] have presenters answer a certain number of questions in English," "I wanted to do a group presentation," and "If we do it, we should assign chapters to individual students [rather than having students choose a chapter from the textbook]. Otherwise we end up collecting similar information about the same chapters and [the presentations] become boring." The last comment coincides with the above comments about 
similar presentations; these comments imply that presentation topic options have to be carefully prepared.

\section{Student and Teacher Assessment}

Comparisons between students' self-evaluations and the teacher's evaluations in the final pair presentations revealed interesting findings (Table 2). First, the students' self-evaluations were severer than the teacher's. This tendency was observed in the spring semester, as well (Shimo, 2010). Second, correlation of the teacher's and students' self-evaluation in comprehensibility was very weak $(r=.16)$, while that of content was relatively strong $(r=.56)$. This implies that the students' and teacher's interpretations or understanding of comprehensibility may have been very different. It is possible that students' different confidence levels had a stronger effect on their self-evaluations of comprehensibility compared to those of content. Less confident students may have evaluated their performances more severely even though the performances were more comprehensible than they thought they were. Likewise, Cheng and Warren (2005) reported that students felt less comfortable in their peer assessment activities assessing their peers' language proficiency levels, compared to other non-language related criteria. The researchers attributed this to the students' lack of knowledge about what constituted high and low language proficiency and to their lack of confidence in their own language proficiency. In the current study, the teacher did not evaluate each student's presentation during the actual performance, but by listening to the recorded presentations while referring to a hard copy of the presentation materials; this may also have contributed to the gap.

Table 2

Comparison between Teacher Evaluation and Student Self-Evaluation of Pair Presentations

\begin{tabular}{|c|c|c|c|c|}
\hline \multirow{2}{*}{ Evaluation } & \multicolumn{2}{|c|}{ Content (5 points) } & \multicolumn{2}{|c|}{ Comprehensibility (5 points) } \\
\hline & Teacher & Students & Teacher & Students \\
\hline Mean Score & 3.68 & 3.21 & 3.52 & 3.02 \\
\hline Pearson's Correlation & \multicolumn{2}{|c|}{$r=.56$} & \multicolumn{2}{|c|}{$r=.16$} \\
\hline
\end{tabular}

\section{Conclusion}

Findings in this study have useful implications. First, most students in the study favored simultaneous pair presentations, finding this method helpful for their learning. Students were able to practice more and receive ample feedback in a less threatening atmosphere. However, some students found some repetition boring or unnecessary. To address this, teachers should help students understand the objectives of each step so that students can make the most of the assignment. Teachers should not only explain the purpose, but also offer ample time for reflection (Shimo, 2010).

The problem of some students finding repeat performances rather useless can be partially ascribed to the restricted choice of presentation topics. The students in this study were told to choose a chapter from their textbook, which meant there were only about ten topics to choose from each semester. Some topics were more popular than others, leading to overlapping information in presentations. The overlapping was even more obvious when all presentations were shared in front of the class.

Next, while step-by-step teaching is necessary, students should eventually be exposed to different presentation styles, through which they can learn different strategies and skills. The various responses to the whole-class presentations implied that more motivated or confident students were willing to try various styles of presentations. When designing classroom 
assignments, teachers should consider students' different preferences such as group presentations as well as various future needs. Some students may not like speaking in front of a large audience, but may want to practice it, and some may realize its value only after they have the opportunity.

Finally, this study, as well as Shimo (2010), suggested that there may have been a discrepancy between student and teacher interpretations of assessment criteria. To reduce the impact of potentially low reliability in students' self- and peer assessments in the final course grade of the author's classes, the self-evaluation portion was minimized and peer evaluation was not included. This reliability issue should be investigated further in future studies. A small suggestion for now is that in addition to the teacher simply explaining criteria to the students, dialogues between the teacher and students, and between students, will be helpful (Orsmond et al., 2000; Rust et al., 2003). When students understand what constitutes a successful result, they can make the most of the learning situation.

\section{Author Note}

Etsuko Shimo, Faculty of Applied Sociology, Kinki University, Osaka, Japan.

Correspondence concerning this article should be addressed to Etsuko Shimo, Faculty of Applied Sociology, Kinki University, Kowakae 3-4-1, Higashi Osaka City, Osaka, 557-8502, Japan. Phone: 81-6-6721-2332 (main). E-mail: shimo@socio.kindai.ac.jp 


\section{References}

Apple, M. (2011). The big five personality traits and foreign language speaking confidence among Japanese EFL students (Doctoral dissertation). Available from Proquest Dissertations and Theses database. (UMI No. 3457819)

Brown, I., \& Diem, R. (2009). Oral presentations reinvigorated: An alternative way to conduct and assess student presentations. Studies in Language and Cultures, 24, 79-91.

Cheng, W., \& Warren, M. (2005). Peer assessment of language proficiency. Language Testing 22(1), 93-121. http://dx.doi.org/10.1191/0265532205lt298oa

Horwitz, E. K., \& Young, D. J. (1991). Language anxiety: From theory and research to classroom implications. Upper Saddle River, NJ: Prentice-Hall.

Jacobs, G. M., Power, M. A., \& Loh, W. I. (2002). The teacher's sourcebook for cooperative learning: Practical techniques, basic principles, and frequently asked questions. Thousand Oaks, CA: Corwin Press.

Maclntyre, P. D., \& Gardner, R. C. (1989). Anxiety and second-language learning: Toward a theoretical clarification. Language Learning, 39(2), 251-275. http://dx.doi.org/10.1111/j.1467-1770.1989.tb00423.x

Martinez, G. (2008). Oral presentations in the ESL classroom using a technique similar to speed dating. The Internet TESL Journal, 14(1). Retrieved from http://iteslj.org/Techniques/Martinez-OralPresentations.html

Ministry of Education, Culture, Sports, Science, and Technology (MEXT). (1999). Shin gakushu shido yoryo [New courses of study]. Retrieved from http://www.mext.go.jp/b_menu/shuppan/sonota/990301.htm

Nishino, T. (2009). Communicative language teaching in Japanese high schools: Teachers' beliefs and classroom practices (Doctoral dissertation). Available from Proquest Dissertations and Theses database. (UMI No. 3371994)

Orsmond, P., Merry, S., \& Reiling, K. (2000). The use of student derived marking criteria in peer and self-assessment. Assessment and Evaluation in Higher Education, 25(1), 23-38. http://dx.doi.org/10.1080/02602930050025006

Otoshi, J., \& Heffernen, N. (2008). Factors predicting effective oral presentations in EFL classrooms. The Asian EFL Journal, 10(1), 65-78.

Rust, C., Price, M., \& O'Donovan, B. (2003). Improving students' learning by developing their understanding of assessment criteria and processes. Assessment and Evaluation in Higher Education, 28(2), 147-164. http://dx.doi.org/10.1080/02602930301671

Shimo, E. (2010). Eigo kyoshitsu ni okeru sho guruupu de no happyo no katsuyo [Small-group presentation activities in English classes], Bulletin of Department of General Education, Kinki University, 1(1), 133-149.

Young, D. J. (Ed.). (1999). Affect in foreign language and second language learning: A practical guide to creating a low-anxiety classroom atmosphere. Boston, MA: McGraw-Hill. 


\section{Appendix}

\section{Questionnaire about Individual Presentations (Fall Semester)*}

* This questionnaire was originally written in Japanese and was translated by the author for this paper.

1) In the fall semester, the presentation assignments included the following steps. Do you think each step was helpful for your learning?

i. Presentations to two different partners in rehearsal

ii. Presentations to two different partners in the "final" stage

iii. Presentation in front of the whole class
1: I strongly disagree.
2: I somewhat disagree.
3: I disagree.
4: I agree.
5: I somewhat agree.
6: I strongly agree.

Do you think each step was helpful for your learning? Circle the appropriate number and write reasons for your response.

i. Presentations to two different partners in rehearsal

Reasons for your response

ii. Presentations to two different partners in the "final" stage

$1 \quad 2 \quad 3 \quad 4 \quad 5 \quad 6$

Reasons for your response

iii. Presentation in front of the whole class

$\begin{array}{llllll}1 & 2 & 3 & 4 & 5 & 6\end{array}$

Reasons for your response

2) What did you learn from the presentation assignments?

3) What did you find difficult in the presentations?

4) Write any opinions or suggestions you have about ways of conducting presentations. 